\title{
Crime e policiamento durante a pandemia de COVID-19 no Rio de Janeiro, Brasil
}

\author{
Crime and police activity during the COVID-19 pandemic in Rio \\ de Janeiro, Brazil
}

Joana da Costa Martins Monteiro (https://orcid.org/0000-0001-8768-4852) ${ }^{1}$

Eduardo Fagundes de Carvalho (https://orcid.org/0000-0002-5182-1357) ${ }^{1}$

Ramón Chaves Gomes (https://orcid.org/0000-0001-6976-4904) ${ }^{2}$
${ }^{1}$ Centro de Ciência Aplicada à Segurança Pública, Fundação Getúlio Vargas. R. da Candelária 6, Edifício Octávio Gouvêa de Bulhões, Centro. 20091-020 Rio de Janeiro RJ Brasil. joana.monteiro@fgv.br ${ }^{2}$ Observatório Fluminense, Universidade Federal Rural do Rio de Janeiro. Seropédica RJ Brasil.

\begin{abstract}
This paper analyzes crime reports and police activity in Rio de Janeiro during the first months of the COVID-19 pandemic. The results indicate there was an overall drop in crime rates starting in April, especially in property crimes, which plummet to extremely unusual levels when compared with previous patterns. This pattern is most likely associated with an unprecedented decline in public mobility in some areas of the state. We show that the most significant reductions in street robberies occurred in neighborhoods where there was a greater decline in presence on the streets. Measures of police activity, in particular drug seizures and different types of arrests, displayed a reduction comparable with the drop in criminal indicators. In contrast, the number of police killings followed a unique pattern: in April, immediately after the adoption of social distance measures, this indicator increased above the average from the previous four years; as of May, however, it assumed a downward trend, which turned into extraordinarily low levels in June. The extreme variation in the use of force by the police during the pandemic reinforces the documented dissonance between police lethality and criminal dynamics in Rio de Janeiro, shedding light on the mechanisms that regulate police violence in the state.
\end{abstract}

Key words Public Security, COVID-19, Violence
Resumo Este trabalho analisa os indicadores de Segurança Pública no Rio de Janeiro durante os primeiros meses da pandemia de COVID-19. Os resultados demonstram uma queda ampla nos indices de atividade criminal a partir de abril, em especial nos delitos contra o patrimônio, cujo nível de ocorrência foi particularmente incomum para o padrão anterior dos dados. Esse comportamento parece estar associado à retração no fluxo de pessoas em áreas do estado. Para os bairros em que se tem informação de deslocamento, é possivel demonstrar que as reduções mais expressivas de roubos de rua ocorreram onde houve maior diminuição na circulação de pessoas. As atividades policiais registraram uma redução semelhante aos indicadores criminais, em particular as apreensões de drogas e as prisões. A exceção a esse cenário foi representada pelo número de mortes por intervenção de agentes do Estado: em abril, esse indicador observou um aumento superior à média dos últimos quatro anos; a partir de maio, entretanto, assumiu um movimento de queda, que se transformou em um desempenho extraordinariamente baixo em junho. A oscilação no uso da força pelas polícias reforça a dissonância entre a letalidade policial e as dinâmicas criminais no Rio de Janeiro, configurando-se como um contexto relevante para a compreensão da violência policial fluminense.

Palavras-chave Segurança Pública, COVID-19, Violência 


\section{Introdução}

O Governo do estado do Rio de Janeiro adotou, em 13 de março de 2020, regras de distanciamento social com o objetivo de desacelerar a curva de contágio do novo coronavírus (Sars-CoV-2), o que incluiu restrições à circulação em áreas públicas e o fechamento do comércio não-essencial. No mês seguinte à adoção dessas medidas, foi registrado um aumento de $50 \%$ na média do índice de isolamento social do estado ${ }^{1}$. A redução do nível de deslocamento urbano na capital e nos demais municípios fluminenses afetou diretamente um amplo conjunto de dinâmicas sociais - desde as atividades econômicas até os padrões criminais.

À medida em que diversas áreas do estado apresentaram queda no número de casos e de óbitos relacionados à enfermidade, novas diretrizes governamentais foram publicadas a partir de junho flexibilizando o isolamento e ampliando gradativamente os serviços presenciais. A despeito da retomada das atividades, no entanto, dados preliminares sugerem que a repercussão da pandemia e das medidas para contê-la se estenderá no tempo, reconfigurando diferentes aspectos $\mathrm{da}$ vida nas cidades².

Os impactos da pandemia e das medidas de distanciamento social impõem uma série de mudanças na rotina das pessoas e das cidades, com inúmeras consequências sociais e econômicas ${ }^{3}$. Do ponto de vista da dinâmica do crime, é possível se guiar pela teoria econômica e de criminalidade para entender como o cometimento de delitos pode ser afetado pela pandemia de COVID- $19^{4}$. Por um lado, o isolamento social para conter o avanço do vírus provocou uma forte redução no número de pessoas nas ruas, o que diminuiu os alvos e o retorno financeiro das atividades criminosas que ocorrem em vias públicas. Por outro lado, crimes que ocorrem em ambientes domésticos e virtuais tendem a crescer com o aumento da interação dentro dos domicílios e das transações na internet. Da mesma forma que o isolamento social altera a exposição das vítimas, ele também pode afetar o engajamento de novas pessoas nas atividades ilegais, especialmente aquelas que perderam renda devido ao desemprego e à retração econômica. Estudos feitos para diversas cidades norte-americanas e colombianas ${ }^{5,6}$ mostram que diversas ocorrências criminais caíram de forma expressiva, enquanto as ocorrências de homicídio tiveram comportamento mais errático. Inúmeros estudos apontam também para o aumento de casos de violência doméstica.
Instigado por esse cenário, o presente trabalho tem como objetivo principal analisar os indicadores de crime e atividade policial no Rio de Janeiro nos meses anteriores e posteriores ao início das estratégias para reduzir a transmissão do Sars-CoV-2 no Rio de Janeiro. Para além de analisar o comportamento do crime, busca-se analisar como a atividade policial foi afetada durante o período de isolamento social e em que medida essa alteração está em consonância com a evolução das ocorrências criminais durante esse período. Espera-se assim contribuir para o entendimento sobre a relação entre dinâmicas criminais e ações policiais no estado.

\section{Metodologia}

Trata-se de um estudo que busca examinar como evoluíram os indicadores de criminalidade violenta e de atividade policial no Rio de Janeiro após as medidas de distanciamento social para a contenção do novo coronavírus. Esse exercício implica analisar, em comparação com períodos anteriores, as variações no comportamento dos dados a partir da emergência sanitária associada à pandemia de COVID-19. Para isso, utilizou-se informações do Instituto de Segurança Pública (ISP-RJ) sobre ocorrências criminais e atividades policiais registradas no estado entre janeiro de 2016 e junho de 2020. As análises são apresentadas a partir de três unidades geográficas distintas: o estado do Rio de Janeiro, bairros da cidade do Rio de Janeiro e as Áreas Integradas de Segurança Pública (AISP), que equivale à área de atuação de um batalhão da Secretaria de Estado de Polícia Militar. As diferentes escolhas se devem à disponibilidade dos dados e à adequação ao escopo das perguntas de pesquisa.

O ISP-RJ é o órgão fluminense responsável por compilar e disponibilizar mensalmente as principais estatísticas criminais no Rio de Janeiro. Os indicadores extraídos da página virtual da autarquia foram organizados nos seguintes eixos: a) crime contra a vida (Homicídio doloso, Latrocínio, Lesão corporal seguida de morte, Homicídio culposo, Lesão corporal e Estupro); b) crime contra o patrimônio (Roubo de rua, Roubo de veículos, Roubo de carga, Roubo à residência $\mathrm{e}$ Estelionato); e c) atividade policial (Apreensão de drogas, Prisão em flagrante, Mandados de prisão, Apreensão de fuzis e Mortes por intervenção de agentes do Estado).

A escolha dos indicadores obedeceu principalmente a dois critérios: precisão para informar 
mudanças nas dinâmicas criminais e relevância para a gestão da segurança pública no estado. Em primeiro lugar, a taxa de registros e a natureza dos crimes aqui considerados permitem observar com maior segurança as variações ocorridas no fenômeno. Para outros tipos de ocorrência criminal, as estratégias de distanciamento social para conter o novo coronavírus podem ter afetado os registros nas delegacias, o que comprometeria o teor das análises. Em segundo lugar, os Crimes Violentos Letais Intencionais (Homicídio doloso, Latrocínio, Lesão corporal seguida de morte) e os indicadores de Roubos de veículo, de rua e de carga são definidos pelo Sistema Integrado de Metas como os indicadores estratégicos das polícias fluminenses ${ }^{7}$.

Para facilitar a comparação entre fenômenos que possuem dimensões distintas, como os crimes de roubo e os homicídios dolosos, os exercícios aqui desenvolvidos medem a variação de cada delito em relação a seu próprio comportamento usual, considerando como parâmetro as ocorrências mensais entre janeiro de 2016 e junho de 2020. Por isso, as análises empregam o conceito estatístico de Z-score, um recurso que nivela a variabilidade dos dados e permite comparar indicadores que apresentam patamares discrepantes de ocorrência e de variação temporal. De acordo com essa métrica, quando o número de casos de determinado crime é igual a sua média histórica, o Z-score assume o valor zero (0). A diferença em relação a zero (0) é calculada em termos de desvios - padrão, uma medida própria de cada conjunto de dados que expressa a dispersão regular dos casos em relação à média. Sob determinadas hipóteses estatísticas, a presença de uma observação com mais de dois desvios-padrão de diferença para a média, seja para mais ou para menos, pode ser interpretada como um evento cuja probabilidade de ocorrer é inferior a 5\%. Utilizando esse recurso, é possível demonstrar, para diversos indicadores, se os valores registrados no período da pandemia de COVID-19 consistem ou não em eventos atípicos a sua própria trajetória.

As probabilidades associadas aos valores de Z-score estão apoiadas em hipóteses específicas sobre a distribuição estatística das ocorrências. Nesse caso, assume-se implicitamente que os dados seguem distribuição normal e ignora-se a possibilidade de autocorrelação das observações, de modo a simplificar a interpretação do fenômeno observado. Essas afirmações poderiam ser consideradas fortes caso o objetivo do trabalho fosse modelar o mecanismo gerador dos dados, gerar previsões períodos à frente ou fazer inferência causal. Como se busca apenas fornecer métricas padronizadas para identificar variações atípicas, tais hipóteses simplificadoras cumprem o objetivo de facilitar a análise de eventos de desvio-padrão maiores do que 2 .

Com o objetivo de entender o que explica a variação entre os indicadores criminais do estado, foram utilizados dados sobre o fluxo de pessoas captados por câmeras em vias públicas compilados pela empresa Cyberlabs e disponíveis a partir de janeiro de 2020. Esses dados registram o número de pessoas nas ruas a cada 15 minutos, o que torna possível agregar as contagens por mês e bairro e verificar se aumentos ou quedas no número de pessoas nas ruas estão correlacionadas com variações nos indicadores criminais. As informações da Cyberlabs, porém, não cobrem todo o território do estado, mas apenas os bairros do Centro, Flamengo, Botafogo, Copacabana, Ipanema-Leblon, Tijuca, Barra da Tijuca e Jacarepaguá, situados na capital fluminense. Dado o baixo número de bairros e o fato de estarem situados em áreas mais ricas e menos violentas da cidade, o escopo da análise se limitou, nesse caso, a crimes com registros mais frequentes nos bairros monitorados, como Roubo de rua. Ainda que a amostra de bairros não seja representativa do território fluminense e o período coberto se restrinja aos primeiros meses de 2020, o exercício permite colher evidência sugestiva do mecanismo por trás das variações dos indicadores criminais durante os primeiros meses da pandemia no estado.

\section{Resultados}

Os principais indicadores de crimes contra a vida e contra o patrimônio no Rio de Janeiro apresentaram entre março e junho de 2020 números muito inferiores à média mensal dos últimos cinco anos (2016-2020). A Tabela 1 destaca os meses com ocorrência acima de dois desvios-padrão da média aferida entre 2016 e 2020 para os principais indicadores que mensuram os crimes contra o patrimônio e contra a vida no estado.

Todas as ocorrências, a exceção de casos pontuais, apresentaram uma tendência à redução neste ano, que antecede o cenário de pandemia, mas que se acentua significativamente a partir dela. Os indicadores de Estupro e de Lesão corporal apresentaram em abril e maio, respectivamente, reduções três vezes maiores que seus padrões históricos de variação. Isso significa que a probabilidade desses indicadores registrarem um declínio dessa magnitude é menor do que $0,1 \%$ em tempos 
Tabela 1. Variação de indicadores de crimes contra o patrimônio e contra a vida (Z-Score) entre janeiro e junho de 2020, estado do Rio de Janeiro.

\begin{tabular}{lccccccccc}
\hline & \multicolumn{4}{c}{ Crimes contra o patrimônio } & \multicolumn{4}{c}{ Crimes contra a vida } \\
\cline { 2 - 9 } Período & $\begin{array}{c}\text { Roubo } \\
\text { de Rua }\end{array}$ & $\begin{array}{c}\text { Roubo de } \\
\text { veículos }\end{array}$ & $\begin{array}{c}\text { Roubo } \\
\text { de carga }\end{array}$ & Estelionato & $\begin{array}{c}\text { Roubo à } \\
\text { residência }\end{array}$ & CVLI & $\begin{array}{c}\text { Homicídio } \\
\text { culposo }\end{array}$ & $\begin{array}{c}\text { Lesão } \\
\text { corporal }\end{array}$ & Estupro \\
\hline jan/20 & $-0,2$ & $-0,6$ & $-0,7$ & 1,4 & $-1,1$ & $-0,6$ & $-0,8$ & 0,2 & $-0,4$ \\
fev/20 & $-0,4$ & $-1,0$ & $-1,5$ & 0,8 & $-1,7$ & $-1,1$ & $-0,4$ & 0,2 & 0,1 \\
mar/20 & $-1,4$ & $-1,5$ & $-1,8$ & 0,1 & $-1,2$ & $-0,4$ & $-1,5$ & $-1,3$ & $-0,9$ \\
abr/20 & $-2,7$ & $-2,2$ & $-1,9$ & $-0,7$ & $-1,9$ & $-1,3$ & $-1,6$ & $-2,7$ & $-3,3$ \\
mai/20 & $-2,8$ & $-2,5$ & $-1,3$ & 0,8 & $-2,4$ & $-2,0$ & $-1,6$ & $-3,1$ & $-2,9$ \\
jun/20 & $-2,6$ & $-2,4$ & $-1,6$ & 3,4 & $-2,8$ & $-2,2$ & $-1,1$ & $-2,3$ & $-0,4$ \\
\hline
\end{tabular}

Fonte: Elaborado pelos autores com base nos dados do Instituto de Segurança Pública (ISP-RJ).

normais e sob as considerações atestadas na seção metodológica. Os Crimes Violentos Letais Intencionais (CVLI), que compreende o Homicídio doloso, o Latrocínio e a Lesão corporal seguida de morte, apresentaram uma redução expressiva em maio e junho. Após a implementação de diretrizes para frear a transmissão do Sars-CoV-2, apenas os números de Roubo de carga e de Homicídio culposo não apresentaram variações dessa magnitude. Em direção oposta aos demais, o crime de estelionato registrou em junho um aumento extremamente atípico.

A principal hipótese para essa variação brusca nos indicadores é que a menor circulação de pessoas nas ruas, em função das medidas de distanciamento social, tenha reduzido a oportunidade para o cometimento de delitos. A escassez de dados de fluxo de pessoas para todos os territórios do estado torna difícil testar essa hipótese. A empresa Cyberlabs, porém, compila informações que permitem identificar o nível da circulação de pessoas em oito bairros da capital do estado durante o primeiro semestre de 2020 (Centro, Flamengo, Botafogo, Copacabana, Ipanema-Leblon, Tijuca, Barra da Tijuca e Jacarepaguá). A contagem é realizada através de câmeras da prefeitura espalhadas na cidade. A partir de seu cruzamento com as informações das áreas de delegacias de polícia, é possível verificar se, entre os bairros cobertos pela Cyberlabs, há uma relação direta entre o fluxo de pessoas e a ocorrência de Roubo de rua. Caso isso se confirme, é esperado que os meses em que os bairros registraram maior diminuição da circulação de pessoas sejam, em média, os meses com maior redução desse crime.

O Gráfico 1 mostra que essa relação é bastante forte para alguns bairros da capital fluminense. Os polígonos e letras no gráfico marcam as variações no fluxo de pessoas (eixo horizontal) e no total de Roubos de rua (eixo vertical) para cada bairro em relação a fevereiro, o mês imediatamente anterior aos decretos governamentais de distanciamento social. $\mathrm{O}$ símbolo $\mathrm{X}$ diz respeito aos valores para os bairros em janeiro. Como esperado, essas são as observações mais próximas do zero no eixo horizontal, isto é, aquelas que registraram a menor variação no deslocamento de pessoas em relação a fevereiro. Os quadrados fechados, os quadrados abertos, os triângulos e os pontos registram as variações para os meses de março, abril, maio e junho, respectivamente.

É possível observar no gráfico uma associação positiva entre as variáveis de crime e deslocamento: nos meses e bairros em que a redução na circulação de pessoas foi maior houve, em média, maior queda também nos Roubos de rua (coeficiente de correlação de 0,73). A título de exemplo, o bairro do Centro registrou em abril, quando comparado a fevereiro, queda de $86 \%$ nos dois indicadores. Embora baseado em uma amostra pequena de bairros selecionados por um curto período, trata-se de uma evidência sugestiva em favor da importância do fluxo de pessoas na variação observada nos indicadores criminais, sobretudo porque, controlando para efeitos fixos de bairro e mês, uma queda de $10 \%$ no fluxo de pessoas nas ruas está, em média, associada a uma queda de 7,8\% nos roubos de rua. Tal resultado reforça a tese que compreende esse tipo de delito, principalmente, como um crime de oportunida$\mathrm{de}^{8}$.

Considerando que as reduções de crimes contra a vida e contra o patrimônio são objetivos estratégicos das Secretarias de Estado de Polícia Civil e Militar no Rio de Janeiro, e tendo em vista o comportamento atípico desses índices nos meses de abril, maio e junho, torna-se igualmente relevante examinar os números da atividade policial no momento subsequente às medidas de distanciamento social. 


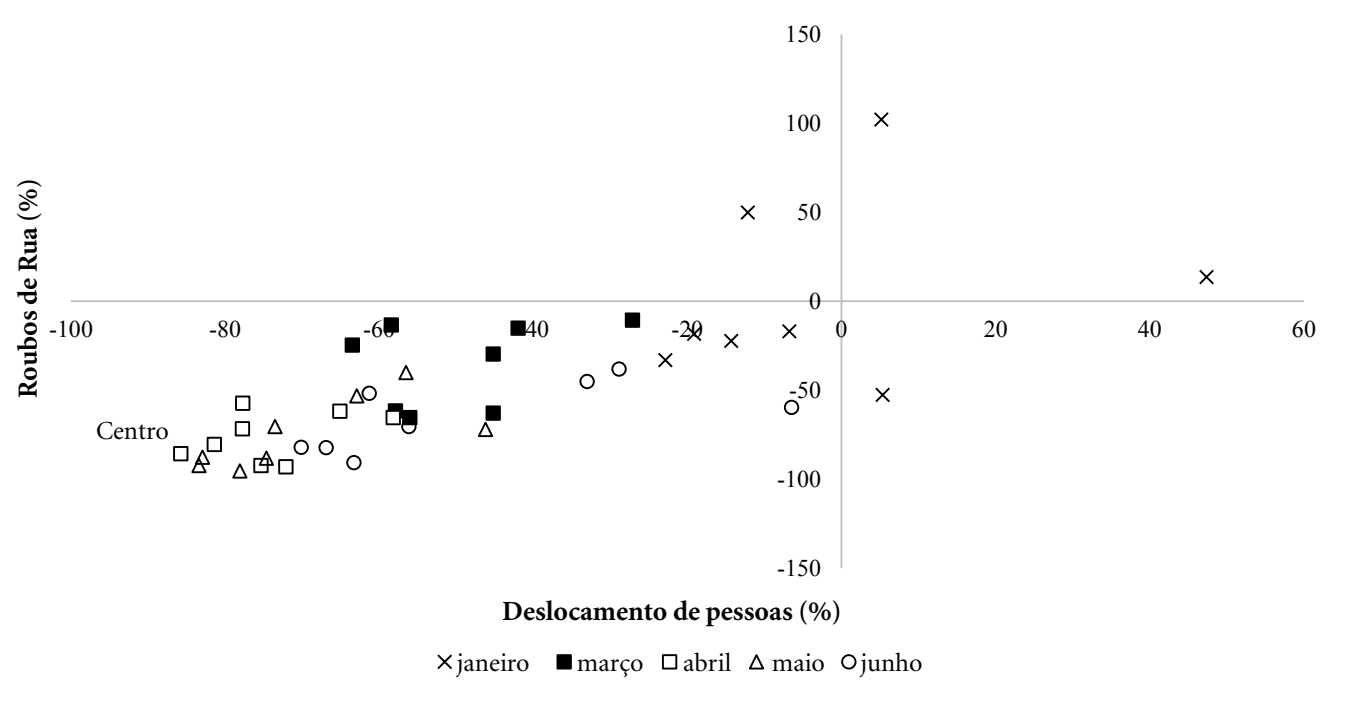

Gráfico 1. Variação percentual de deslocamento de pessoas x variação percentual de Roubo de rua por bairro e por mês de 2020 (em relação a fevereiro/2020), estado do Rio de Janeiro.

Fonte: Elaborado pelos autores com base nos dados da empresa Cyberlabs e do Instituto de Segurança Pública (ISP-RJ).

O Gráfico 2 recupera o conceito de Z-Score para examinar a evolução dos principais indicadores de atividade policial no território fluminense após as intervenções para limitar a propagação de COVID-19. É possível observar que esses indicadores registraram uma redução intensa de dois ou mais desvios-padrão em relação à média entre 2016 e 2020 . Houve uma queda acentuada em Apreensão de drogas (-2 desvios-padrão em março, abril e junho), em Prisão em flagrante ( -2 em abril e - 3 em maio e junho) e em Mandados de prisão ( -3 em abril e -2 em maio e junho). $\mathrm{O}$ indicador de Apreensão de fuzis também manifestou uma variação negativa, embora o resultado tenha estado dentro do padrão regular dos dados, a não ser em junho, quando as ocorrências registraram um valor atipicamente baixo.

Ao contrário dos indicadores criminais e das demais atividades policiais, que manifestaram nesse período uma tendência generalizada ao declínio, o total de Morte por intervenção de agente do Estado apresentou um movimento flutuante: inicialmente, registrou uma variação positiva e alta no mês de abril - 1,7 desvios-padrão acima da média observada entre 2016 e 2020. No mês seguinte, no entanto, o indicador apresentou um valor próximo a zero, que se transformou em uma redução incomum em junho, com um decréscimo de 2,1 desvios-padrão em relação à média.

Esses dados sugerem que, nos três primeiros meses da pandemia do novo coronavírus, o uso da força letal pelas polícias trilhou um caminho próprio e independente dos números da criminalidade violenta e dos demais indicadores de atividade policial. Chama a atenção a redução de mais de 2 desvios-padrão na apreensão de drogas em abril, mesmo mês em que as mortes por intervenção de agente de Estado dispararam na Região Metropolitana. A série histórica revela ainda dois movimentos opostos em 2020: um descolamento inicial entre indicadores frequentemente associados e, em seguida, uma reaproximação entre eles em junho.

Esse quadro assimétrico pode informar variações locais nos indicadores analisados. Isto é, o crescimento no número total de mortes pela polícia poderia representar uma resposta estatal ao recrudescimento das atividades criminais em determinados bairros e áreas do estado. O Gráfico 3 descreve localmente a relação entre o comportamento dos crimes contra a vida e a evolução da letalidade policial a partir de abril. As Áreas Integradas de Segurança Pública (AISP) ${ }^{9}$ estão distribuídas segundo as variações nos indicadores de CVLI (eixo horizontal) e de Mortes por intervenção de agentes do Estado (eixo vertical). Caso esses indicadores apresentassem algum tipo de associação entre si, seria possível identificar uma linha, ascendente ou descendente, no entorno da qual os polígonos deveriam se concentrar. A delimitação geográfica de cada AISP reproduz a área de atuação de um batalhão da Secretaria de Estado de Polícia Militar (SEPM). 


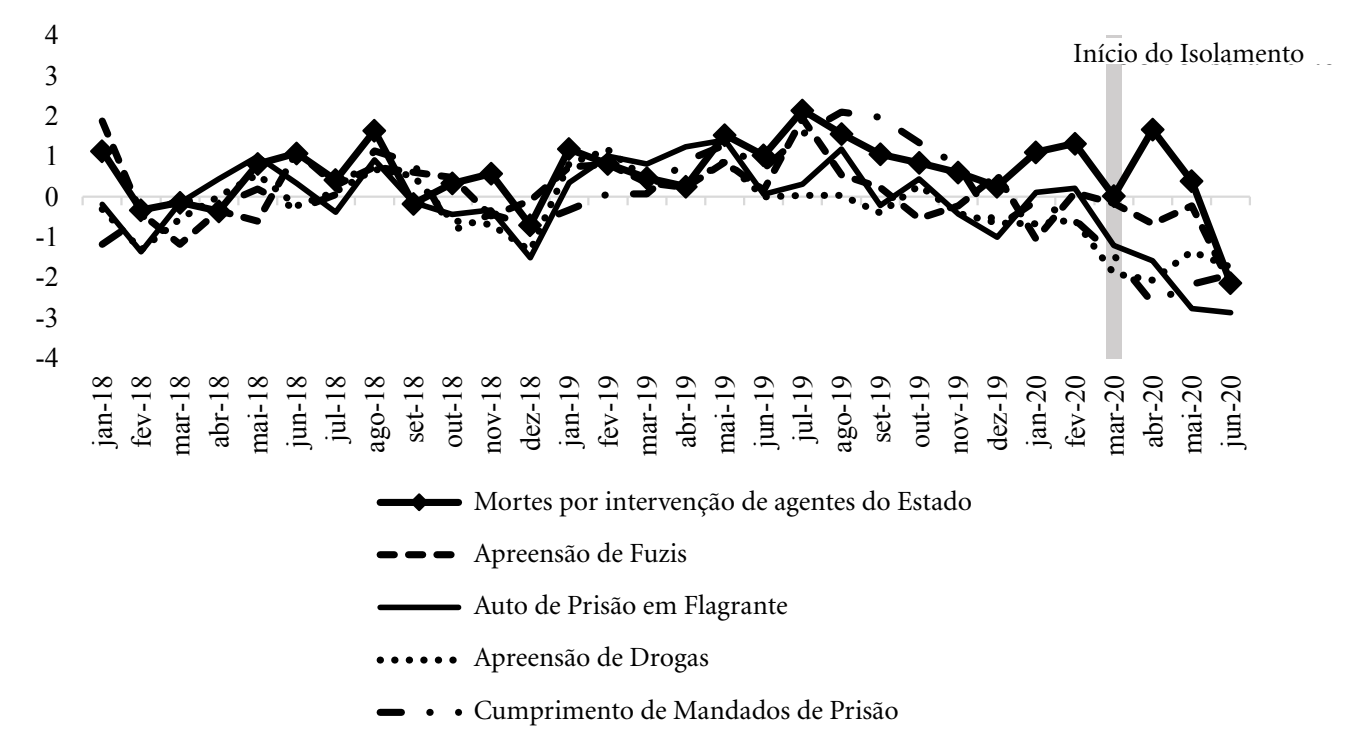

Gráfico 2. Série histórica de Indicadores de atividade policial e de criminalidade violenta.

Variação da média em desvio padrão considerando período entre 2016 e 2020, estado do Rio de Janeiro.

Fonte: Elaborado pelos autores com base nos dados do Instituto de Segurança Pública (ISP-RJ).

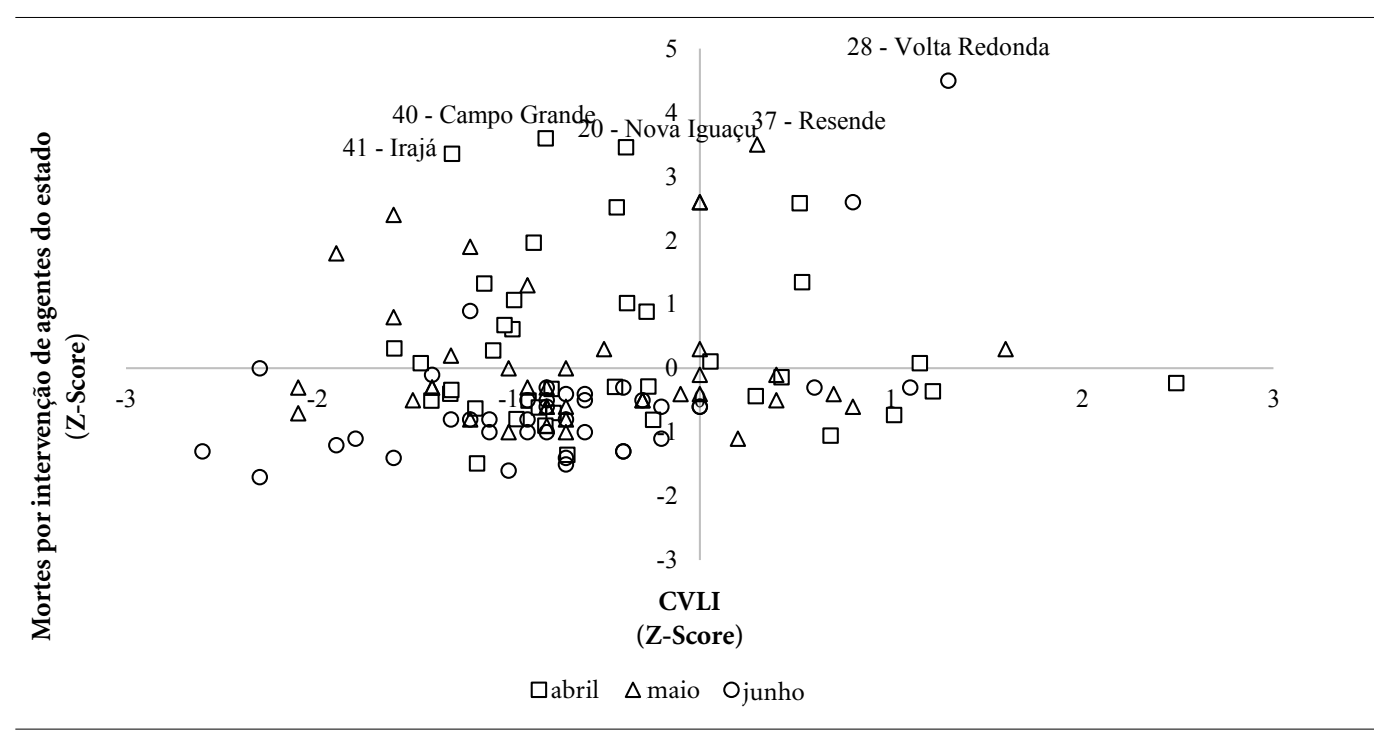

Gráfico 3. Variação de CVLI e de Morte por intervenção de agente do Estado em abril, maio e junho de 2020 por AISP, estado do Rio de Janeiro.

Fonte: Elaborado pelos autores com base nos dados do Instituto de Segurança Pública (ISP-RJ).

Os polígonos à direita da linha vertical obtiveram variação positiva no número de CVLI em relação à sua média. Os polígonos acima da linha horizontal obtiveram variação positiva no número mortes por intervenção de agentes do Estado em relação à sua média. Isso significa que as observações no quadrante superior esquerdo indicam as AISP que tiveram aumento no número mortes por agentes do Estado e queda no número de CVLI. No polo oposto, o quadrante inferior 
direito abriga as AISP que tiveram redução no indicador de Mortes por intervenção de agentes do Estado e aumento nos números de CVLI.

A dispersão das AISP sem padrão observável nos meses de abril, maio e junho indica que as duas variáveis, reciprocamente, não apresentaram correlação relevante no período (coeficiente de correlação de 0,18 ). Os crimes contra a vida registraram variações negativas em quase todas as áreas, e em muitas delas uma redução bastante inferior à média verificada entre 2016 e 2020. As Mortes por intervenção de agente do Estado, entretanto, não estiveram relacionadas às práticas criminais. Embora haja uma discreta inclinação positiva nos polígonos acarretada pelos resultados de junho, essa associação vai na direção contrária do lugar-comum, segundo o qual, maior enfrentamento público reduz o número de crimes.

O Gráfico 4 permite observar em separado a amplitude da variação local registrada nas Mortes por intervenção de agente do Estado entre abril e junho de 2020. O tamanho das barras equivale ao padrão de variação próprio de cada área. Os pontos em preto correspondem à média local da letalidade policial dos últimos quatro anos, enquanto os quadrados, triângulos e círculos representam, respectivamente, os números para os meses de abril, maio e junho. Quando as observações registram variações superiores a dois desvios-padrão - eventos bastante improváveis em condições usuais - os polígonos aparecem localizados fora da barra, seja acima ou abaixo dela. Isso facilita a identificação de variações atípicas, tanto nos locais em que as ocorrências são mais frequentes, quanto naqueles onde elas possuem um volume baixo de registro.

Em abril, as AISP Tijuca (6) e Magé (34) registraram uma variação positiva na letalidade da ação policial superior a dois desvios-padrão. Em termos estatísticos, isso caracteriza a observação de um evento cuja chance de ocorrer é inferior a 5\%. Nas AISP Campo Grande (40), Nova Iguaçu (20) e Irajá (41), os registros indicam uma distância ainda maior em relação à média histórica, superando a magnitude de três desvios-padrão, o

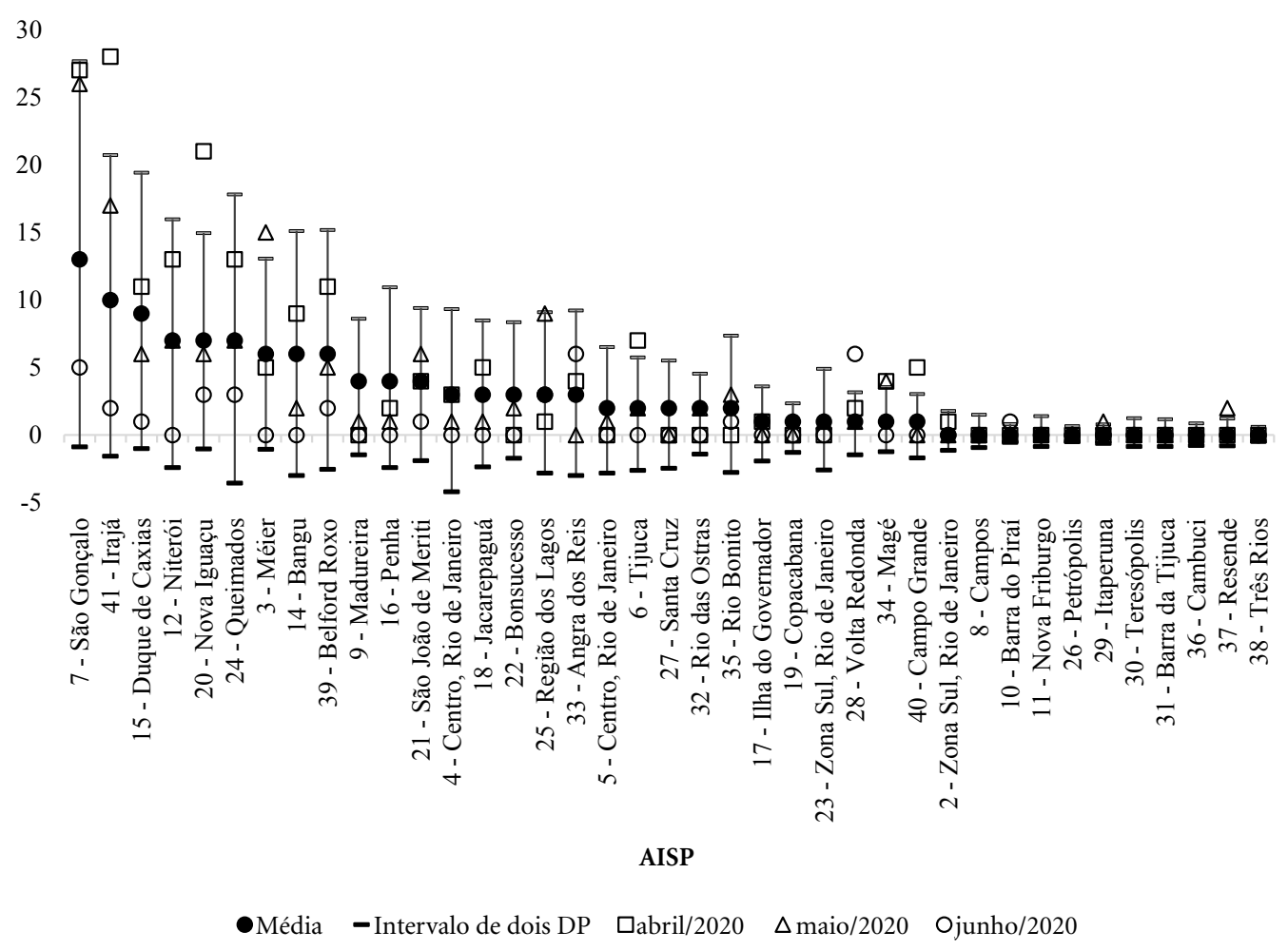

Gráfico 4. Variação nas Mortes por intervenção de agente do Estado por AISP entre abril e junho de 2020 em relação à sua média entre 2016 e 2020, estado do Rio de Janeiro. 
que representa uma probabilidade de ocorrência inferior a 1\%. A AISP São Gonçalo (7), embora não tenha excedido formalmente os limites estabelecidos, registrou uma variação igualmente acentuada. Juntas, essas seis AISP corresponderam a $51,4 \%$ do total da letalidade policial registrada naquele mês no estado - 91 casos em um universo de 177 , por sua vez o segundo maior valor registrado pela série temporal do indicador.

No mês seguinte, as variações atípicas no uso da força letal pelas polícias foram menos frequentes e observadas principalmente fora da Região Metropolitana do estado, como nas AISP Resende (37) e Itaperuna (29). Na capital e arredores, destacam-se as ocorrências excepcionais registradas no Meier (3) e em Magé (34). A AISP São Gonçalo (7) permaneceu novamente no limiar da escala, mas com um valor absoluto bastante alto. Em junho, correspondendo ao declínio no volume do indicador, boa parte das AISP registram números inferiores as suas médias históricas. Somente em Volta Redonda (28) e Barra do Piraí (10) houve aumento incomum de casos. Apesar de representarem variações inusuais às trajetórias dos dados, esses números são pouco expressivos em termos absolutos, o que se depreende do total de Mortes por intervenção de agente do Estado observada nesse mês - 34 ocorrências -, o menor valor mensal em seis anos.

\section{Discussão}

A análise apresentada nesse trabalho indica que ocorrências criminais apresentaram forte queda a partir de abril de 2020. Os crimes contra o patrimônio apresentaram em abril e maio, respectivamente, reduções de mais de dois desvios-padrão, enquanto indicadores de Estupro e de Lesão corporal caíram mais de três desvios-padrão. Os Crimes Violentos Letais Intencionais (CVLI) apresentaram uma redução expressiva em maio e junho. Os indicadores de atividade policial como cumprimentos de mandado, apreensões de drogas e de armas também experimentaram forte redução. Apenas as mortes por intervenção de agentes do Estado seguiram trajetória própria e aumentaram fortemente em abril de 2020.

O desempenho atípico apresentado pelos crimes violentos e por boa parte das ações policiais parece estar associado às circunstâncias excepcionais do momento, especialmente à retração sem precedentes no fluxo de pessoas em áreas do estado. Analisando os dados da empresa Cyberlabs sobre deslocamento para alguns bairros do município do Rio de Janeiro, é possível demonstrar que as reduções mais expressivas de roubos de rua ocorreram nos bairros onde houve maior diminuição na circulação de pessoas. Embora o número restrito de bairros e meses com informações de deslocamento de pessoas prejudique testes mais robustos dessa hipótese, os resultados fortalecem a interpretação em favor da importância da retração do fluxo de pessoas na queda dos indicadores criminais de roubo

A redução das ocorrências criminais no Rio de Janeiro é similar à encontrada em outros lugares do mundo, como em cidades na Colômbia ${ }^{5}$ e nos Estados Unidos (EUA) ${ }^{6}$, e em outras regiões brasileiras, como nos estados de São Paulo, Minas Gerais, Rio Grande do Sul e Amazonas ${ }^{10}$, que também adotaram nesse período medidas restritivas para a contenção do novo coronavírus.

Abrams $^{6}$ analisou o comportamento de 15 indicadores criminais em 25 cidades dos EUA ao longo da pandemia de COVID-19. Em comparação com os anos anteriores, ocorrências de roubos a residências, de furtos e de crimes relacionados a drogas caíram de forma expressiva. Entre os crimes violentos, houve queda no número de lesões corporais dolosas, mas as ocorrências de homicídio e tiroteios não tiveram variação estatisticamente significativa quando comparadas ao padrão dos anos anteriores.

Alvarado et al. ${ }^{5}$, ao analisar o caso colombiano, mostram que diversos indicadores criminais registraram uma queda expressiva após as medidas de distanciamento social no país. Entre março e agosto de 2020, os homicídios diários por município reduziram $16 \%$ em média se comparados à tendência anterior. A redução nas ocorrências de homicídios foi maior em áreas urbanas e entre indivíduos do sexo masculino. $\mathrm{O}$ roubo de carro registrou, no mesmo período, uma queda de $45 \%$ distribuída por todas as regiões. A produtividade policial observou uma redução relevante em termos de quantitativo de prisão, a não ser nos casos relacionados ao cumprimento de medidas sanitárias, que aumentaram significativamente.

A queda de crimes patrimoniais identificada nesses estudos pode ser interpretada à luz da teoria econômica que investiga como os incentivos afetam o cometimento de delitos ${ }^{4,8}$. $\mathrm{O}$ isolamento social para conter a pandemia de COVID-19 provocou uma forte redução no número de pessoas nas ruas, o que diminuiu os alvos e o retorno financeiro das atividades criminosas. $\mathrm{O}$ efeito negativo desse choque poderia ter sido compensado em parte pelo engajamento de novas pessoas nas atividades ilegais, especialmente aquelas que per- 
deram renda devido ao desemprego e à retração econômica. Os dados indicam, entretanto, que o efeito da queda de oportunidade para o cometimento de delitos foi bastante superior aos efeitos de outros determinantes.

No Rio de Janeiro, o comportamento independente das Mortes por intervenção de agentes do Estado em meio à pandemia de COVID-19 corrobora os resultados apresentados por Monteiro et al. ${ }^{11}$, que sinalizam para a baixa associação, no nível local, entre a letalidade policial e os indicadores de criminalidade violenta no Rio de Janeiro. Analisando o período entre 2003 e 2019, os autores demonstram que incrementos no uso da força letal pelas polícias não são acompanhados de quedas posteriores nos crimes contra o patrimônio e contra a vida. Ao contrário, para alguns indicadores, o aumento nas mortes provocadas pelas polícias está correlacionado à maior atividade criminal, embora nesse caso a magnitudes dos efeitos seja baixa.

No quadro da pandemia de COVID-19, formado por circunstâncias bastante excepcionais, a baixa vinculação entre essas dimensões se torna ainda mais nítida. Mesmo com uma queda relevante e sustentada nos principais indicadores de crimes desde abril, a letalidade policial no estado seguiu em ascensão, atingindo valores muito acima da média em determinadas regiões. Em maio, o número se aproximou de seu padrão nos últimos anos (2016-2020), o que representou uma queda em relação ao mês anterior, mas ainda insuficiente para retirá-lo de um patamar historicamente elevado. Entretanto, em junho, a letalidade da ação policial registrou uma redução extraordinária, superior a dois desvios-padrão da média, que se distribuiu de forma consistente entre praticamente todas as AISP do estado.

Com o objetivo de clarificar esse percurso singular da letalidade policial no primeiro semestre de 2020, Monteiro et al. ${ }^{12}$ analisam a participação semanal das polícias em ocorrências de tiroteios na Região Metropolitana do estado. Coletado pela plataforma Fogo Cruzado, esse indicador mostra variações consistentes com o comportamento do número oficial de Mortes por intervenção de agentes do Estado. Imediatamente após o primeiro decreto estadual instaurando medidas de distanciamento social, há uma queda não sustentada na participação de agentes públicos em tiroteios, que logo volta a patamares elevados em abril e nas primeiras semanas de maio. Em seguida, o número de casos dessa natureza entra em declínio e permanece extraordinariamente baixo nas semanas de junho, em consonância com o resultado atípico dos dados oficiais compilados pelo ISP-RJ.

O declínio da presença de policiais em confrontos armados coincide com uma reunião noticiada pelos jornais cariocas entre o governador Wilson Witzel e a cúpula da Segurança Pública fluminense. Nela, o chefe do executivo estadual teria determinado a interrupção de incursões policiais durante a realização de ações humanitárias em favelas ${ }^{13}$. Nas semanas seguintes, o volume de tiroteios envolvendo a polícia seguiu baixo após a decisão do ministro Edson Fachin de limitar as operações policiais no estado ${ }^{14}$. Esse último aspecto, em particular, dado o seu caráter extremo, foi extensamente abordado por diversos analistas $^{15}$, mas o comportamento atípico da tropa antes mesmo da judicialização da atuação policial joga luz também para a influência da linha de comando sobre o desempenho das polícias nas ruas.

Considerando o retrospecto da Segurança Pública fluminense nas últimas décadas ${ }^{16,17}$ é possível dizer que o uso da força letal pelas polícias no Rio de Janeiro apresenta características de uma endemia - ocorre de forma contínua no tempo e com incidência expressiva no território. Isso renova a relevância dos exercícios que buscam expandir a compreensão sobre os mecanismos reguladores da violência policial no estado. Nesse sentido, com o propósito de pavimentar o caminho para novas investigações, sinaliza-se a seguir para duas características do fenômeno que adquiriram destaque durante a emergência sanitária provocada pelo novo coronavírus: a concentração territorial das mortes provocadas pelas polícias e a atribuição da linha de comando nos resultados da ação policial.

Em primeiro lugar, como é típico de agravos endêmicos, o uso da força letal pelas polícias experimenta surtos eventuais. Algo semelhante a isso parece ter ocorrido em determinadas regiões, especialmente no mês abril, quando o número de mortes provocadas pelas polícias atingiu valores muito acima da média, mesmo em locais onde níveis excessivos são recorrentes. Episódios dessa natureza assinalam para o fato de que a letalidade policial não se distribui de forma homogênea no território, como mostram diversos trabalhos publicados sobre o tema ${ }^{18,19}$.

Em tese, a incidência de casos estaria relacionada principalmente às dinâmicas da criminalidade violenta local, mas a baixa associação entre o fenômeno e os indicadores criminais denota a influência decisiva de outros elementos, como fatores de caráter organizacional e corporativo, 
que em geral prescindem de critérios de eficiência $^{18,20}$. Esse aspecto, em particular, reforça a necessidade de investigar de forma sistemática os procedimentos e resultados da ação policial, com o intuito de identificar as situações e os comportamentos que estimulam o uso da força letal pelas polícias.

Em segundo lugar, quanto aos condicionantes mais gerais da letalidade policial, sobressai no contexto analisado a contribuição da linha de comando sobre a manutenção ou redução da violência policial. Segundo Cano et al. ${ }^{21}$, diferentes escalas de comando podem afetar o desempenho da tropa em diversos aspectos, inclusive no uso da força letal. A sincronia observada entre a ordem do Governador fluminense e a queda na participação de policiais em confrontos armados sinaliza, em alguma medida, para a vitalidade das estruturas de controle interno e externo sobre o uso excessivo da força pelas polícias - apesar dos obstáculos bem documentados sobre o funcionamento adequado desses mecanismos ${ }^{22}$.

Analisando o dado semanalmente, é possível verificar que a redução de tiroteios envolvendo policiais ocorre aproximadamente 10 dias antes da decisão do ministro Edson Fachin (STF). Isso renova o entendimento de que a postura administrativa e política do alto comando - governador, secretário estadual, comandante de polícia etc. - pode ter uma repercussão bastante intensa sobre o nível da letalidade policial, como já foi observado também em outros momentos da história recente ${ }^{23}$.

\section{Conclusão}

Os dados aqui reunidos indicam que as dinâmicas criminais se arrefeceram de forma consistente em todo o estado do Rio de Janeiro nos três meses subsequentes aos esforços governamentais para contenção do novo coronavírus. Não raro, essas reduções representaram uma variação negativa incomum, superior a dois desvios-padrão.
Esse resultado é similar ao encontrado em outros lugares do mundo que também adotaram medidas restritivas contra a propagação de Sars-Cov-2 nesse período.

Contração semelhante pode ser observada também nos números que monitoram a produtividade policial, que revelaram uma tendência forte e sustentada de queda, particularmente em relação aos indicadores de prisão e de apreensão de drogas e armas. Dentre o conjunto de aspectos analisados, apenas a letalidade da ação policial se manteve indiferente ao choque representado pela pandemia de COVID-19.

O desempenho atípico apresentado pelos crimes violentos e por boa parte das ações policiais parece estar associado às circunstâncias excepcionais do momento, especialmente à retração sem precedentes no fluxo de pessoas em áreas do estado. Analisando os dados da empresa Cyberlabs sobre deslocamento na capital, é possível demonstrar, por exemplo, que as reduções mais expressivas de roubos de rua ocorreram nos bairros onde houve maior diminuição na circulação de pessoas.

No entanto, o que poderia explicar o comportamento independente no uso da força letal pelas polícias após a adoção de medidas de distanciamento social? As análises aqui apresentadas indicam que em abril de 2020 a polícia aumentou o uso da força sem justificativa clara e sem isso estar correlacionado com surtos de crime. Esse aumento foi interrompido em junho de forma brusca e atípica, respondendo a questões político-judiciais. Assim, dentre os indicadores de Segurança Pública, o indicador de Morte por intervenção de agentes de Estado foi o único que teve comportamento próprio, sem relação com pandemia de COVID-19 e as excepcionalidades provocadas por ela na vida social. Esse resultado renova os desafios para a compreensão e o enfrentamento ao uso excessivo da força letal pelas polícias fluminenses, especialmente no que se refere à geografia das mortes pelas polícias e ao papel das hierarquias institucionais no uso da força pelos agentes. 


\section{Colaboradores}

JCM Monteiro: concepção do artigo e revisão crítica do manuscrito. EF Carvalho: coleta e análise dos dados e revisão final do artigo. RC Gomes: redação, revisão de literatura e revisão final do artigo. Todos os autores aprovaram a versão final do estudo.

\section{Referências}

1. Inloco. Índice de isolamento social através de geolocalização de celulares [Internet]. [acessado 2020 jun 5]. Disponível em: https://mapabrasileirodacovid.inloco. com.br/.

2. Instituto Brasileiro de Geografia e Estatística (IBGE). Painel de indicadores: variação do PIB [Internet]. [acessado 2020 set 06]. Disponível em: https://www. ibge.gov.br/indicadores\#variacao-do-pib.

3. Fuchs-Schündeln N, Krueger D, Ludwig A, Popova I. The long-term distributional and welfare effects of COVID-19 school closures. Working Paper Series [Internet]. National Bureau of Economic Research; 2020 [acessado 2020 out 6] Disponível em: https://www. nber.org/papers/w27773.

4. Draca M, Machin S. Crime and economic incentives. Ann Rev Econom 2015; 7(1):389-408.

5. Alvarado N, Norza E, Perez-Vicent S, Tobón S, Vanegas-Arias M. Evolución de la seguridad ciudadana en Colombia en tiempos del COVID-19. Nota técnica [Internet]. 2020 [acessado 2020 ago 28]. Disponível em: https://publications.iadb.org/publications/spanish/ document/Evolucion-de-la-seguridad-ciudadana-enColombia-en-tiempos-del-COVID-19.pdf.

6. Abrams D. COVID and Crime: An Early Empirical Look. J Public Econom 2021; 194 (1):1-44.

7. Rio de Janeiro. Secretaria de Estado de Segurança. Manual de Procedimentos para o Sistema de Definição e Gerenciamento de Metas para os Indicadores Estratégicos de Criminalidade do Estado do Rio de Janeiro [Internet]. 2016 [acessado 2020 ago 28]. Disponível em: http://arquivos.proderj.rj.gov.br/isp_imagens/Up loads/ManualSIM2016.pdf.

8. Felson M, Clarke RV. Opportunity Makes the Thief Practical theory for crime prevention. Police Research Series Paper 98 [Internet]. 1998 [acessado 2020 ago 28]. Disponível em: https://popcenter.asu.edu/sites/ default/files/opportunity_makes_the_thief.pdf.

9. Instituto de Segurança Pública. Governo do Estado do Rio de Janeiro. Divisão Territorial da Base de Segurança [Internet]. [acessado 2020 jun 6]. Disponível em: http://www.ispdados.rj.gov.br/divisaoTerritorial. html.

10. As mortes violentas mês a mês no país. Monitor da Violência [Internet]. [acessado 2020 ago 28]. Disponível em: http://especiais.g1.globo.com/monitor-daviolencia/2018/mortes-violentas-no-brasil/.

11. Monteiro J, Fagundes E, Guerra J. Letalidade policial e criminalidade violenta. Rev Administr Publica 2020; 54(6):1772-1783.

12. Monteiro J, Fagundes E, Chaves R. Letalidade policial no RJ: como a análise de dados pode contribuir para a interpretação do fenômeno [Internet]. [acessado 2020 set 06]. Disponível em: https://fontesegura.org.br/.

13. Jornal O Dia. Witzel determina que polícias evitem operações em favelas durante ações sociais; grupos divergem [Internet]. [acessado 2020 jul 18]. Disponível em: https://odia.ig.com.br/rio-de-janeiro/2020/05/ 5922211-witzel-determina-que-policias-evitem-operacoes-em-favelas-durante-acoes-sociais--grupos-divergem.html. 
14. Superior Tribunal Federal. Decisão sobre o pedido de Tutela Provisória Incidental na Medida Cautelar na Arguição de Descumprimento de Preceito Fundamental 635/RJ [Internet]. 2020 [acessado 2020 jul 13] Disponível em: http://www.stf.jus.br/arquivo/cms/ noticiaNoticiaStf/anexo/ADPF635DECISaO5DEJUNHODE20202.pdf.

15. Hirata D, Grillo C, Dirk R. Apresentação ao relatório Operações Policiais e Ocorrências Criminais: por um debate público qualificado. DILEMAS 2020; 1-19.

16. Cano I. Letalidade da ação policial no Rio de Janeiro. Rio de Janeiro: ISER; 1997.

17. Centro de Pesquisas do Ministério Público do Estado do Rio de Janeiro (CENPE/MPRJ). Letalidade policial no Rio de Janeiro em 10 pontos [Internet]. [acessado 2020 ago 25]. Disponível em: http://www.mprj. $\mathrm{mp} . \mathrm{br} /$ conheca-o-mprj/centro-de-pesquisas/letalidade-policial-rj.

18. Coelho T. Medindo forças: a vitimização policial no Rio de Janeiro [dissertação]. Rio de Janeiro: Universidade do Estado do Rio de Janeiro; 2017.

19. Gonçalves L. Letalidade violenta e controle ilegal do território no Rio de Janeiro. Cad Seg Publica 2017; 8(1):1-19.

20. Pinc T. Treinamento Policial: um meio de difusão de políticas públicas que incidem na conduta individual do policial de rua. 2011 [tese] São Paulo: Universidade de São Paulo; 2011.

21. Cano I. Letalidade policial no Rio de Janeiro: fatores de influência individual e medidas de controle institucional. Relatório de Pesquisa para o Projeto Pensando a Segurança Pública. Brasília: Senasp, Governo Federal; 2016.

22. Lemgruber J, Musumeci L, Cano I. Quem vigia os vigias: um estudo sobre controle externo da polícia no Brasil. Rio de Janeiro: Record; 2003.

23. Misse DG. A pacificação das favelas cariocas e o movimento pendular na segurança pública. DILEMAS 2019;1:29-52.

Artigo apresentado em 23/09/2020

Aprovado em 07/07/2021

Versão final apresentada em 09/07/2021

Editores-chefes: Romeu Gomes, Antônio Augusto Moura da Silva 